\title{
Paracetamol (acetaminophen) use in infants and children was never shown to be safe for neurodevelopment: a systematic review with citation tracking
}

\author{
Jasmine Cendejas-Hernandez ${ }^{1,2}$ - Joshua T. Sarafian ${ }^{1} \cdot$ Victoria G. Lawton $^{1} \cdot$ Antara Palkar $^{1} \cdot$ Lauren G. Anderson $^{1}$. \\ Vincent Larivière ${ }^{3} \cdot$ William Parker Pa $^{1,2,4}$
}

Received: 23 November 2021 / Revised: 28 January 2022 / Accepted: 1 February 2022 / Published online: 17 February 2022

(C) The Author(s) 2022

\begin{abstract}
Although widely believed by pediatricians and parents to be safe for use in infants and children when used as directed, increasing evidence indicates that early life exposure to paracetamol (acetaminophen) may cause long-term neurodevelopmental problems. Furthermore, recent studies in animal models demonstrate that cognitive development is exquisitely sensitive to paracetamol exposure during early development. In this study, evidence for the claim that paracetamol is safe was evaluated using a systematic literature search. Publications on PubMed between 1974 and 2017 that contained the keywords "infant" and either "paracetamol" or "acetaminophen" were considered. Of those initial 3096 papers, 218 were identified that made claims that paracetamol was safe for use with infants or children. From these 218, a total of 103 papers were identified as sources of authority for the safety claim.

Conclusion: A total of 52 papers contained actual experiments designed to test safety, and had a median follow-up time of $48 \mathrm{~h}$. None monitored neurodevelopment. Furthermore, no trial considered total exposure to drug since birth, eliminating the possibility that the effects of drug exposure on long-term neurodevelopment could be accurately assessed. On the other hand, abundant and sufficient evidence was found to conclude that paracetamol does not induce acute liver damage in babies or children when used as directed.
\end{abstract}

\section{What is Known:}

- Paracetamol (acetaminophen) is widely thought by pediatricians and parents to be safe when used as directed in the pediatric population, and is the most widely used drug in that population, with more than $90 \%$ of children exposed to the drug in some reports.

- Paracetamol is known to cause liver damage in adults under conditions of oxidative stress or when used in excess, but increasing evidence from studies in humans and in laboratory animals indicates that the target organ for paracetamol toxicity during early development is the brain, not the liver.

What is New:

- This study finds hundreds of published reports in the medical literature asserting that paracetamol is safe when used as directed, providing a

foundation for the widespread belief that the drug is safe.

- This study shows that paracetamol was proven to be safe by approximately 50 short-term studies demonstrating the drug's safety for the pediatric liver, but the drug was never shown to be safe for neurodevelopment.

Communicated by Peter de Winter

William Parker

William.Parker@WilliamParkerLab.org

Jasmine Cendejas-Hernandez

jasmine.cendejas.hernandez@duke.edu

Joshua T. Sarafian

joshua.hames@duke.edu

Victoria G. Lawton

victoria.g.lawton@gmail.com

Antara Palkar

antara.palkar@gmail.com

Lauren G. Anderson

lauren.g.anderson@duke.edu
Vincent Larivière

vincent.lariviere@umontreal.ca

1 Department of Surgery, Duke University School of Medicine, Durham, NC, USA

2 WPLab, Inc, 1023 Wells St, Durham, NC 27707, USA

3 École de Bibliothéconomie Et Des Sciences de L'information, Université de Montréal, Montreal, Canada

4 Duke Global Health Institute, Duke University and Duke University Medical Center, Durham, NC 27710, USA 
Keywords Behavior · Neurodevelopment · Infant · Child · Autism

\section{Abbreviations \\ ALT Alanine aminotransferase \\ APAP N-acetyl-para-aminophenol (acetaminophen or paracetamol) \\ AST Aspartate aminotransferase \\ BMI Body mass index \\ BUN Blood urea nitrogen \\ GGT Gamma glutamyltransferase \\ IVH Intraventricular hemorrhage \\ NEC Necrotizing enterocolitis \\ PDA Ductus arteriosus \\ PVL Periventricular leukomalacia \\ ROP Retinopathy of prematurity}

\section{Background}

Most parents and pediatricians currently believe that use of paracetamol in infants and children is safe, promulgating widespread use of the drug in that population. Use of paracetamol in the pediatric populations now exceeds $90 \%$ in some studies [1] and persists even under circumstances in which the drug may have no benefits, such as prophylaxis prior to some vaccinations [2] and treatment of mild fevers [3]. Such beliefs and practices are strengthened and supported by a medical literature which repeatedly asserts without reservation that, when used as directed, the drug is safe in the pediatric population. However, mounting evidence points toward the view that paracetamol exposure during early development can have an adverse effect on neurodevelopment, even when used as directed. For example, in a recent review [4], eight studies supporting a link between prenatal paracetamol exposure and neurodevelopmental problems were identified [5-12]. In the 3 years since that review, at least six additional studies have confirmed this same relationship, three of which have used data from the Norwegian Mother and Child Cohort Study [13-18]. Although exposure to paracetamol in utero is associated with neurodevelopmental problems, even after consideration of potentially confounding factors, the effects are typically small, and the amount of paracetamol required to yield the effect is greater than the amount typically used by average individuals. For example, after adjusting for potential confounders such as parental education level, use of vitamin supplements, parental BMI, smoking, and use of other drugs, Skovlund and colleagues found a weak yet significant association between prenatal exposure to paracetamol and mother-reported communication skills: the chances of being in a lower development category increased with increasing periods of prenatal paracetamol use but not prenatal opioid use [13]. In another example, using propensity score matching, Vlenterie and colleagues found that 28 or more days of paracetamol use during pregnancy was associated with a modestly increased risk of delayed motor milestone attainment (OR: $1.35,95 \%$ CI $1.07-1.70$ ) by children at 18 months [14].

Evidence points toward a higher risk of paracetamolinduced neurodevelopmental disorders when exposure occurs after birth as compared to in utero. Studies using laboratory rodents demonstrate that exposure to near therapeutic doses of paracetamol during the first days of life induces profound, long-term neurological changes [19, 20], whereas somewhat higher doses are required to induce permanent neurological damage during pregnancy [21]. These laboratory studies demonstrate that the target organ for toxicity in neonates is the central nervous system, not the liver, and demonstrate that if paracetamol had been tested using current guidelines, it would never have been approved for use in children. More concerning are observations in children indicating that paracetamol is not safe for neurodevelopment. The 2008 study which first raised a red flag regarding the safety of paracetamol during neurodevelopment found a greater than 20 -fold risk of regressive autism with paracetamol use during childhood [22]. Although this relatively small study did not attract enough interest to promote larger studies, other lines of evidence support the view that paracetamol exposure during early life can lead to neurodevelopmental disorders. For example, a startling twofold greater incidence of infantile autism in circumcised boys compared to non-circumcised boys [23] can be readily explained by potentially negative impacts of paracetamol exposure during and following the circumcision procedure [4]. Sadly, the widely held and entrenched belief that vaccines induce autism [24, 25] may be yet another result of the impact of paracetamol on neurodevelopment in combination with widespread use of the drug during vaccination [4].

With the above concerns in mind, a systematic evaluation of the peer-reviewed literature was initiated to address the question of why paracetamol is widely believed to be safe for use during early development. All papers published between 1974 and 2017 that contained the keywords "infant" and either "paracetamol" or "acetaminophen" were considered. All papers which made claims that paracetamol or acetaminophen is safe for use in infants or children were identified, and the justification for this claim was critically evaluated.

The use of paracetamol predates current safety standards used in the pharmaceutical industry, and even if current standards were applied, those standards do not mandate testing for long-term neurological development. Thus, to those aware of the inner workings of the drug approval process, especially as it has been applied to paracetamol, the results obtained in this study will not be surprising and may even be considered 
by some to be a foregone conclusion that need not be evaluated. Nevertheless, the widespread belief that paracetamol is safe and the resulting widespread use of the drug in the pediatric population is built on the assumption that it is safe for neurodevelopment. With this in mind, this review focuses on unqualified claims of safety in the medical literature that, reasonably, are taken by parents and even many physicians to indicate that the drug is safe for neurodevelopment.

\section{Methods}

As a first step in understanding why paracetamol is thought to be safe during early development, all titles and abstracts in the PubMed ${ }^{\circledR}$ Database with keywords "infant" and "acetaminophen or paracetamol" published between 1974 and 2017 were identified. The term "infant" rather than "child" was selected because (a) the number of papers with the term "child" was prohibitively large, and (b) the focus of the study was intended to be on drug exposure during early development, from birth to age approximately 6 years, not individuals up to the age of 17 years. In all cases, the terms paracetamol and acetaminophen were taken to be synonymous, and no distinctions were made.

In the second step, two coauthors (JCH and JTS) independently screened all titles and abstracts. In this step, articles that could not be obtained in English and all articles not describing use of paracetamol in humans were eliminated from the study. Based on titles and abstracts (if available), articles were tagged which were deemed likely to make claims regarding the safety of paracetamol use in infants and children between birth and age 6 years.

In the third step, two coauthors (JCH and JTS), continuing to work independently, examined full texts of all tagged titles and abstracts. Texts were examined for the following three assertions:

a) Paracetamol use is "safe" in children or infants.

b) Paracetamol is the "drug of choice" in children or infants.

c) Paracetamol use is "recommended" for children or infants.

In cases where the terms "drug of choice" or "recommended" were used, the context was considered. In some cases, particularly in manuscripts expressing caution regarding the use of paracetamol, these terms were not taken to imply safety, but rather were taken to be an indicator of the common acceptance of the drug. These articles were excluded from the study. Based on this approach, articles were tagged that were considered to have made safely claims regarding the use of paracetamol in infants or children younger than 6 years old.
Still working independently, two coauthors (JCH and JTS) evaluated each manuscript making a claim of safety, determining the source of authority for the stated claim. If no literature was cited to support the claim, this was documented. In cases where the source that was cited contained another citation, that secondary reference was obtained and evaluated. This process continued as needed until an original source or sources describing an actual demonstration of safety was identified. An example of the results of this process is shown in Fig. 1.

In the fourth step, any discrepancies between the analyses provided by coauthors JCH and JTS were arbitrated by coauthor WP. In the fifth step, articles upon which safety claims were based were compiled. Finally, articles which made safety claims and articles upon which safety claims were based were evaluated for actual experiments designed to assess safety. For each experiment described, the study group, endpoints measured, and follow-up time were evaluated. Data were graphed and descriptive statistics calculated using GraphPad Prism 8 software. The review was not registered, and the protocol is as described in this Methods section.

\section{Results}

An overview of results from a systematic search for studies demonstrating safety of paracetamol use in infants and children is shown in Table 1. The initial Medline search provided 3096 articles that contained the terms infant and either paracetamol or acetaminophen that were published between 1974 and 2017. From these articles, 467 were selected for assessment based on likelihood of safety claims regarding use of paracetamol in infants or children. Of these 467 articles, 218 made safety claims regarding the use of paracetamol in infants or children. During this phase of the study, numerous articles were identified which either claimed or demonstrated that paracetamol use, even at doses beyond the recommended dose, does not generally cause long-term liver damage in infants or children. Any claims of safety for liver function were not evaluated in detail and were not considered in this study. Only general claims of safety were assessed.

Of the 218 articles making claims that paracetamol use in infants or children is safe, half (114) provided no citation. The other half (114) of the articles cited additional articles as evidence that paracetamol is safe in infants or children. Articles making safety claims as well as articles cited as sources of authority for safety claims were evaluated as described in the Methods. In some cases, the "primary" cited articles did not make original claims of safety, but rather cited additional ("secondary") articles. In cases where a primary article cited another article, the primary article was not considered to 


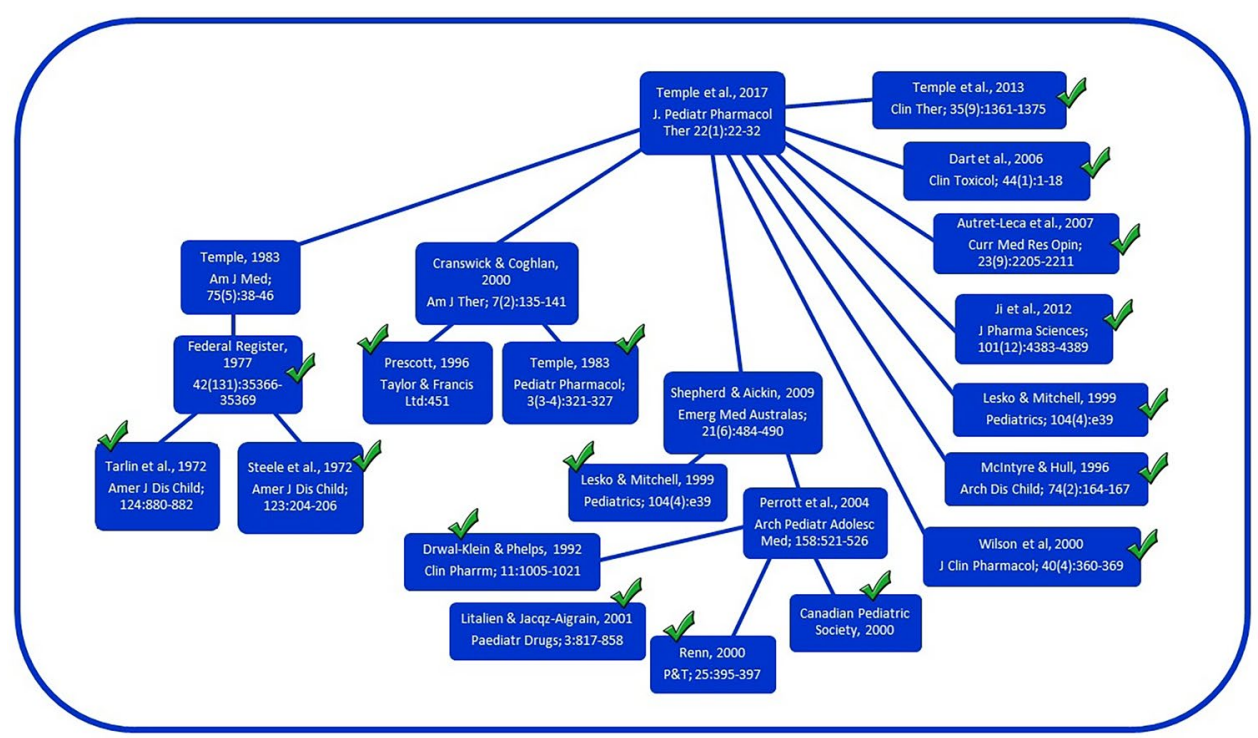

Fig. 1 Flow diagram illustrating connections between articles claiming that paracetamol use is safe for infants or children when used as directed. In this example, the citations in a paper by Temple and colleagues in 2017 [30] are assessed. Articles describing new experiments designed to test safety of paracetamol or which contain claims of safety without citation are included in Table 2 and are indicated by a check mark. Articles shown in the diagram which do not describe experiments designed to test safety of paracetamol and which cite other articles as a source for claims of safety [27, 31, 32, 159] are not included in Table 2 and are not indicted by a check in the diagram have made an original claim of safety, and was not evaluated further. An example of the results of this process is shown in Fig. 1. Both primary articles and secondary (and tertiary, etc.) articles attributed with claims of the safety of paracetamol use in infants or children were compiled and are shown in Table 2. In total, 103 articles were identified which were cited as containing original claims that paracetamol use in infants or children is safe when used as directed. In addition, 16 of the 218 articles with safety claims (a) made those claims based on original experimental evidence and (b) were not cited by other papers. These articles are also included in Table 2, listed at the bottom of the table with zero citations.

Several studies emerged as popular citations for the claim that paracetamol use in infants or children is safe when used as directed. Only 19 articles were cited more than twice, and the most popular article [26] was cited a total of 13 times
(Table 2) by the 218 articles we identified. However, in some cases, well cited articles did not make original claims of safety, and are therefore not included in Table 2. For example, an article by Perrott and colleagues in 2004 [27] was cited a total of 7 total times by the 218 articles we identified. However, Perrott's article, being a review, does not make original claims of safety, but rather cites additional articles as the authority for assurance of safety (Fig. 1). Thus, Perrott's article is not included in Table 2 as an original source for the claim that use of paracetamol is safe for infants and children when used as directed.

Of the 103 articles cited as authority for the safety of paracetamol use in infants or children, 27 did not make claims of safety and did not address safety experimentally (Table 2). Thus, 76 of the 103 articles did address safety, and 48 of these 76 articles (63\%) had already been identified in the
Table 1 Number of citations identified in the systematic search during each step of the study. Numbers are provided for both analysts performing the work (JCH and JTS).

The overlap is the number of citations that were the same between the two analysts

\begin{tabular}{|c|c|c|c|c|}
\hline Step & $\mathrm{JCH}$ & Overlap & JTS & Total \\
\hline 1. Medline (paracetamol + infant) & & & & 3096 \\
\hline 2. Safety claim, first step & 310 & 193 & 350 & 467 \\
\hline 3. Safety claim, second step & 189 & $144(53 *)$ & 189 & 234 \\
\hline 4. Safety claim, final & 173 & $128(37 *)$ & 173 & 218 \\
\hline 5. Sources attributed to safety claim & & & & 103 \\
\hline 6A. Sources with experiments supporting safety claim & & & & 36 \\
\hline $\begin{array}{l}\text { 6B. Safety claim, not cited as a source, with experiments } \\
\text { supporting safety claim }\end{array}$ & & & & 16 \\
\hline
\end{tabular}

*Numbers in parentheses indicated the number of citations in which both analysts identified the same citation, but not the same source or sources as the authority for claims of safety. 


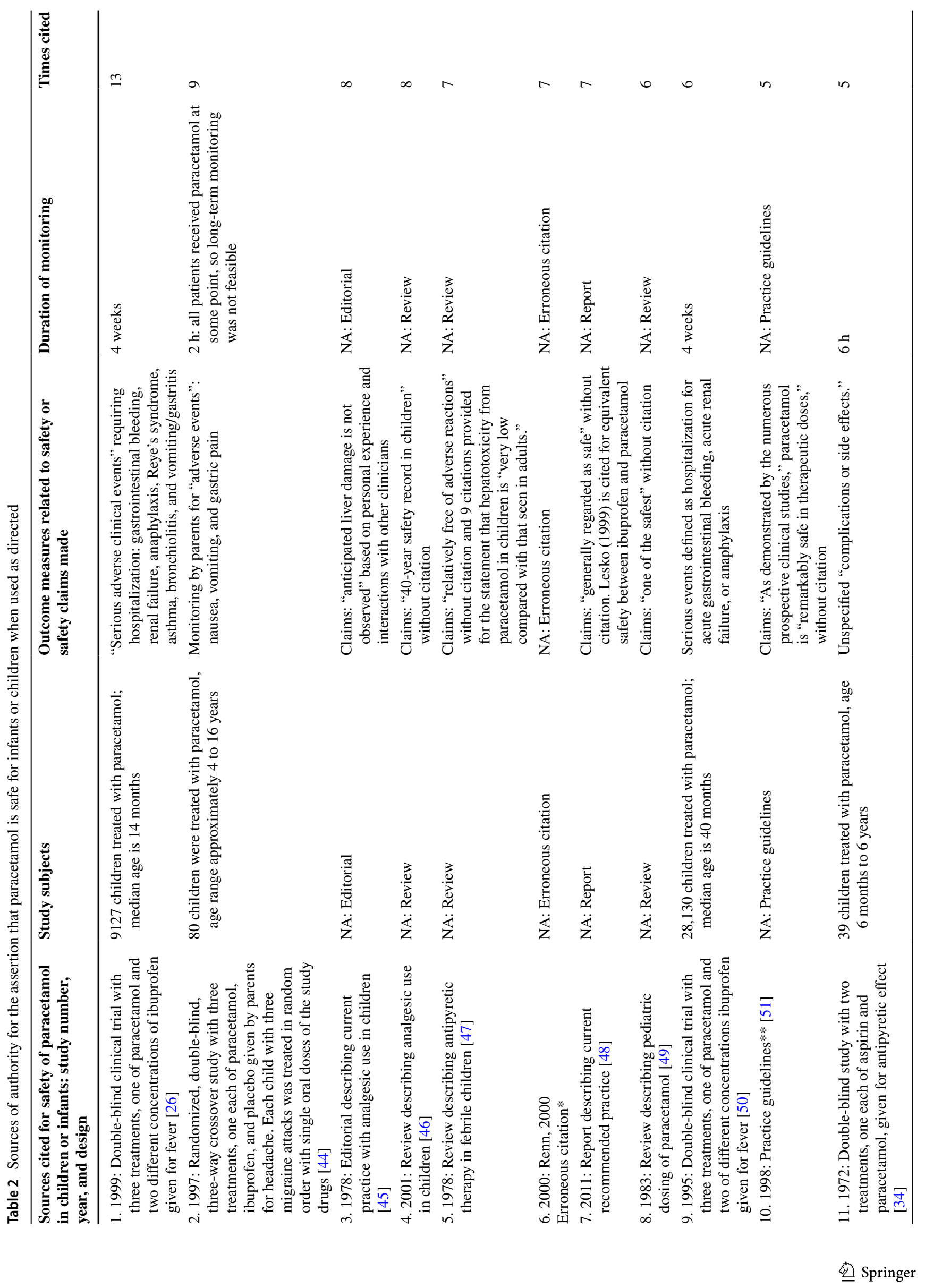




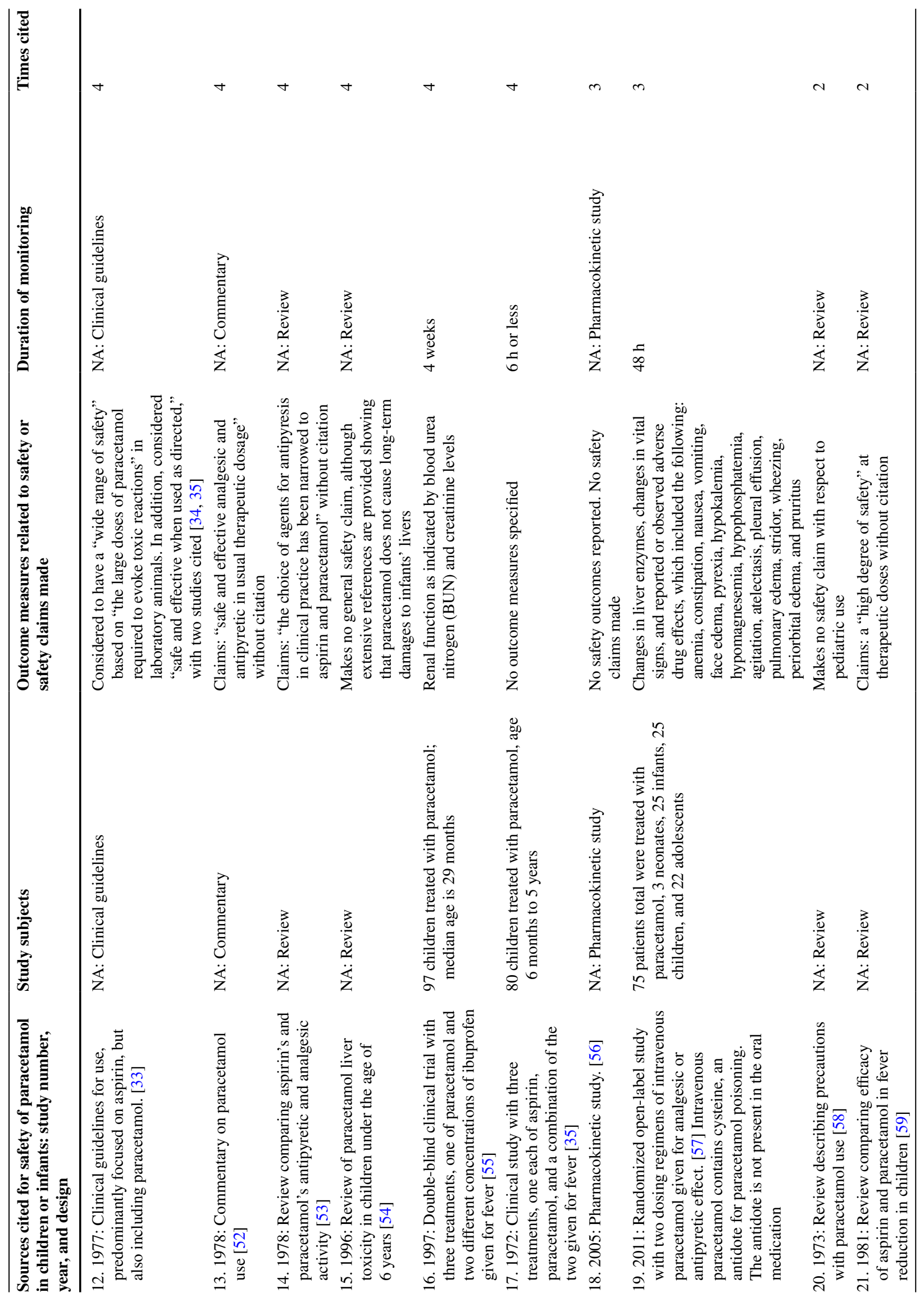




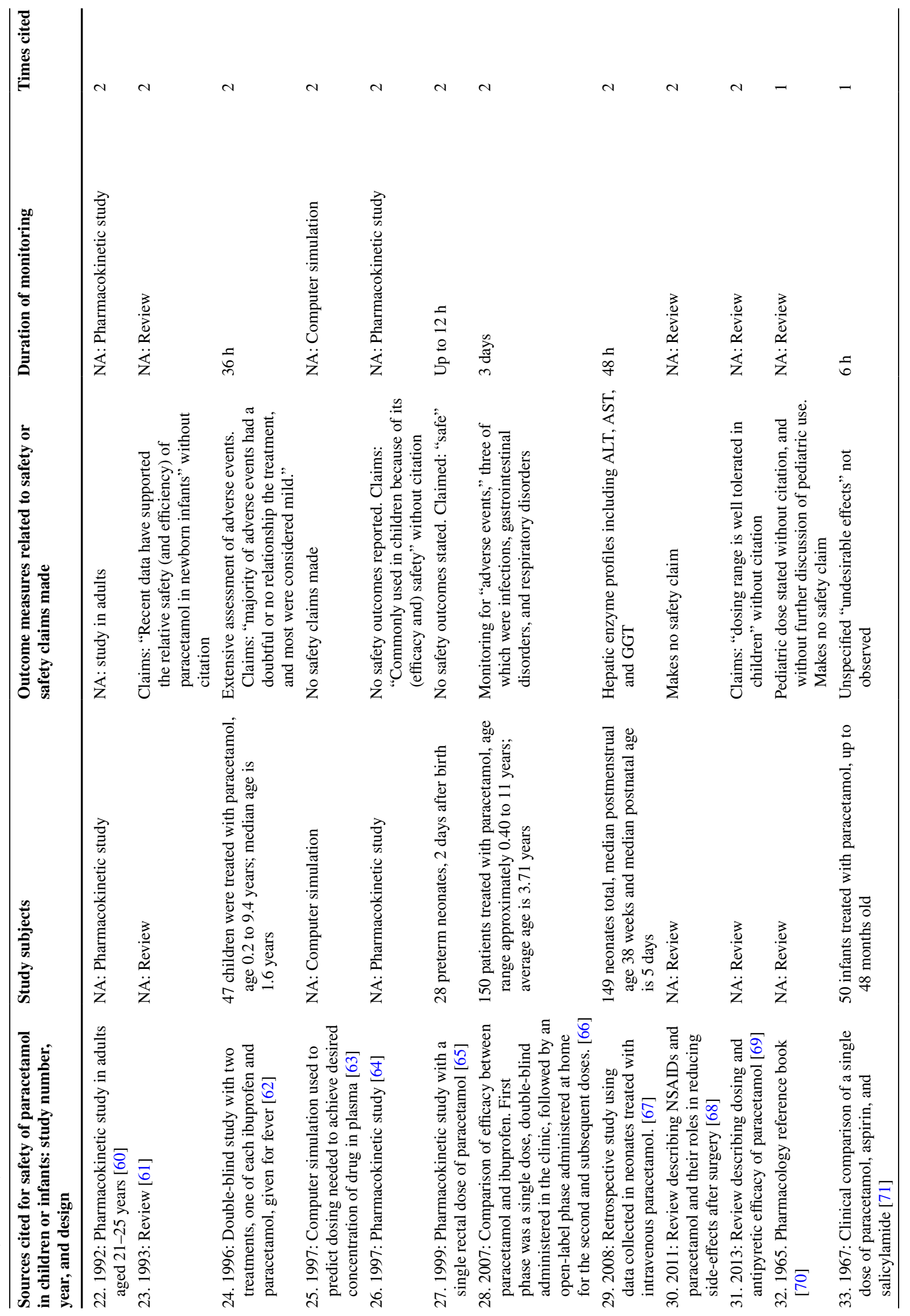




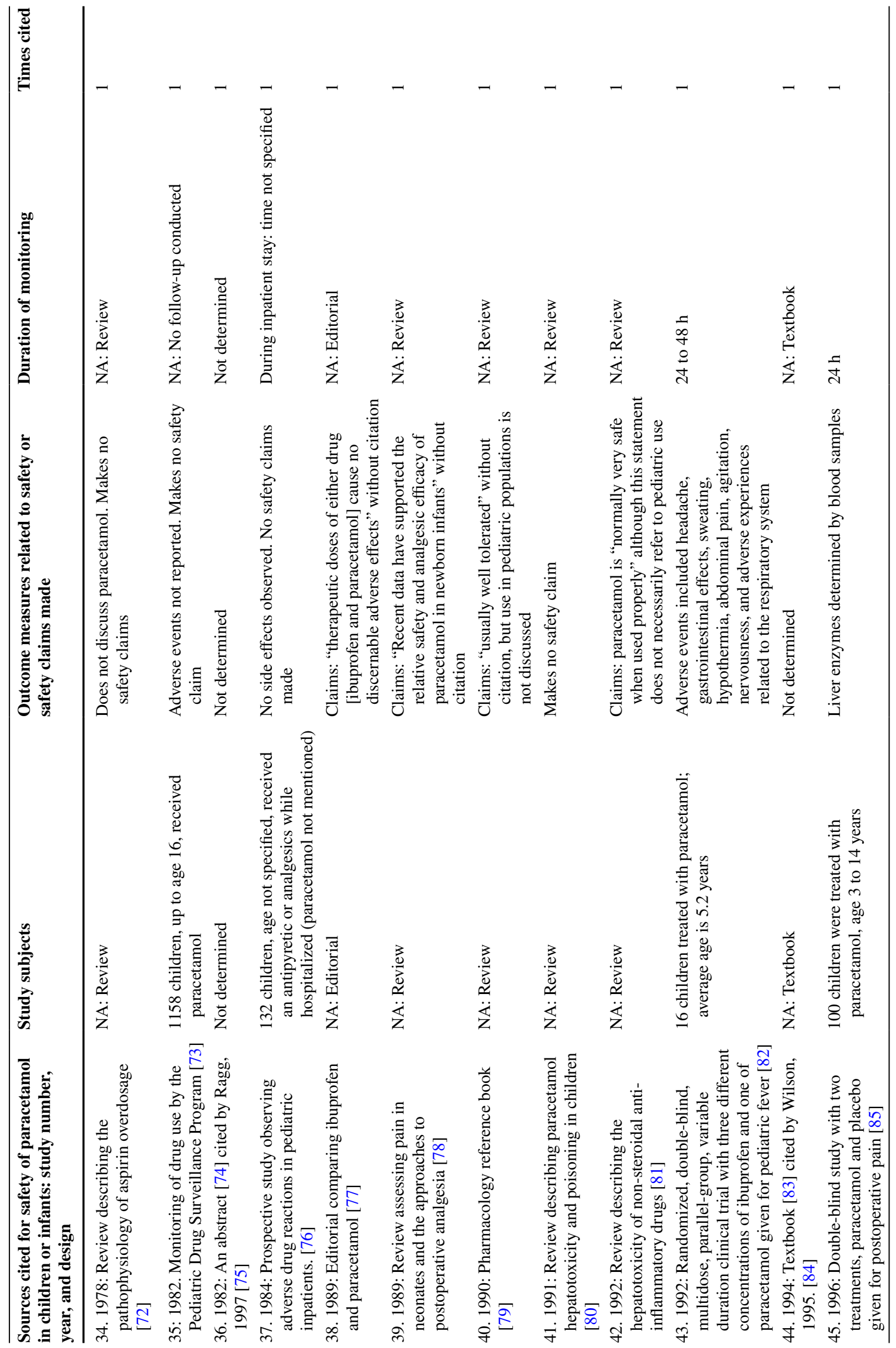




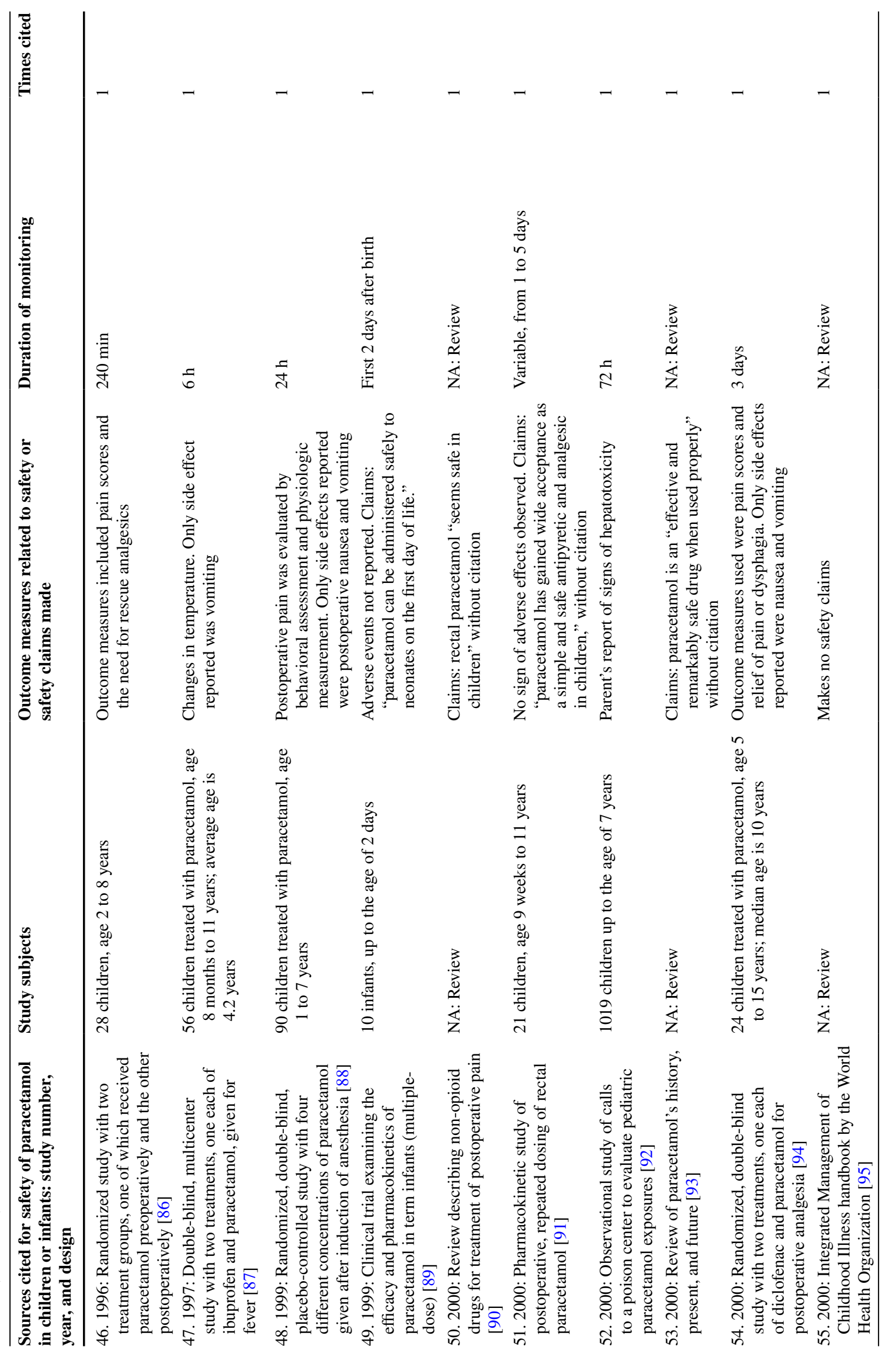




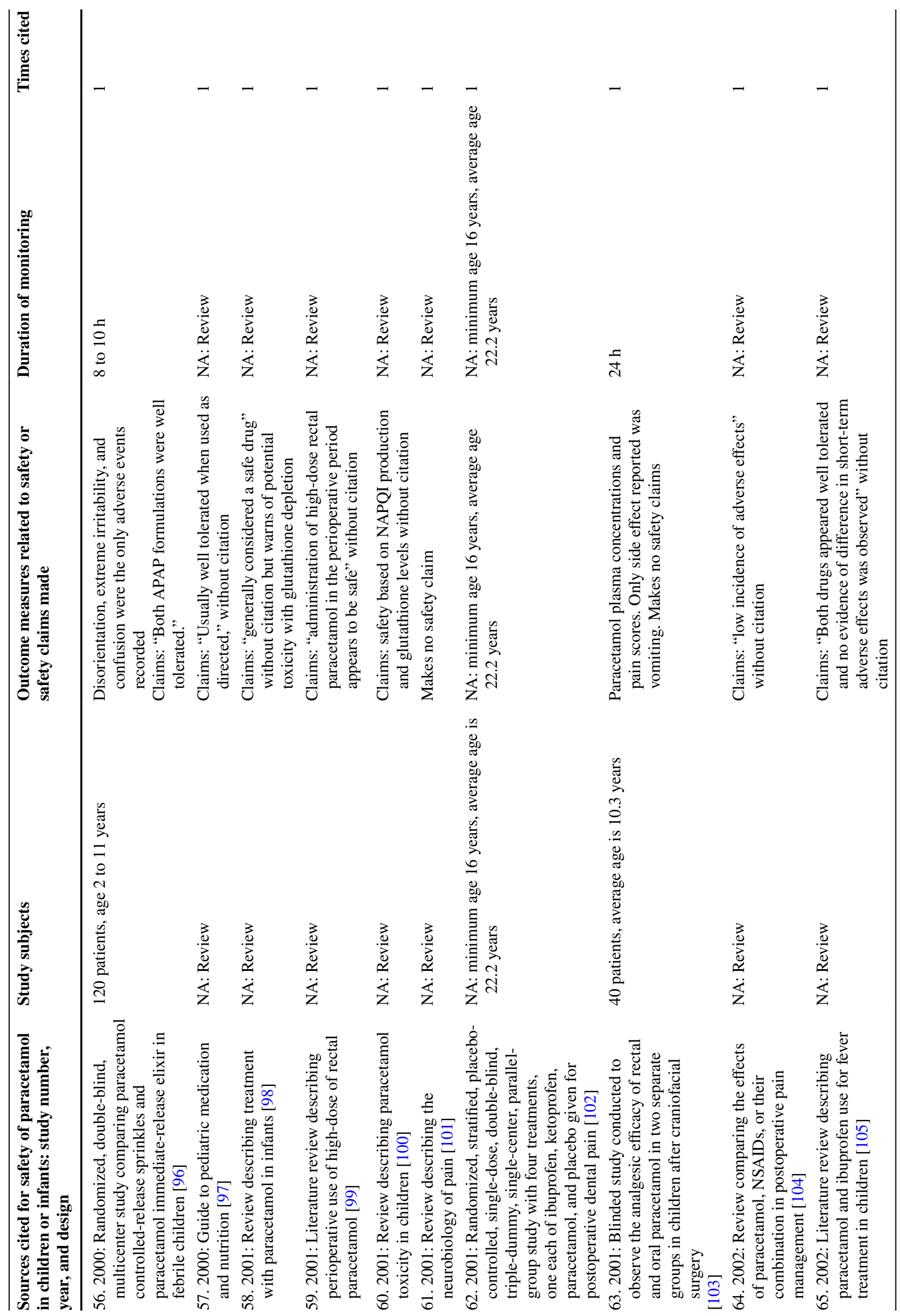




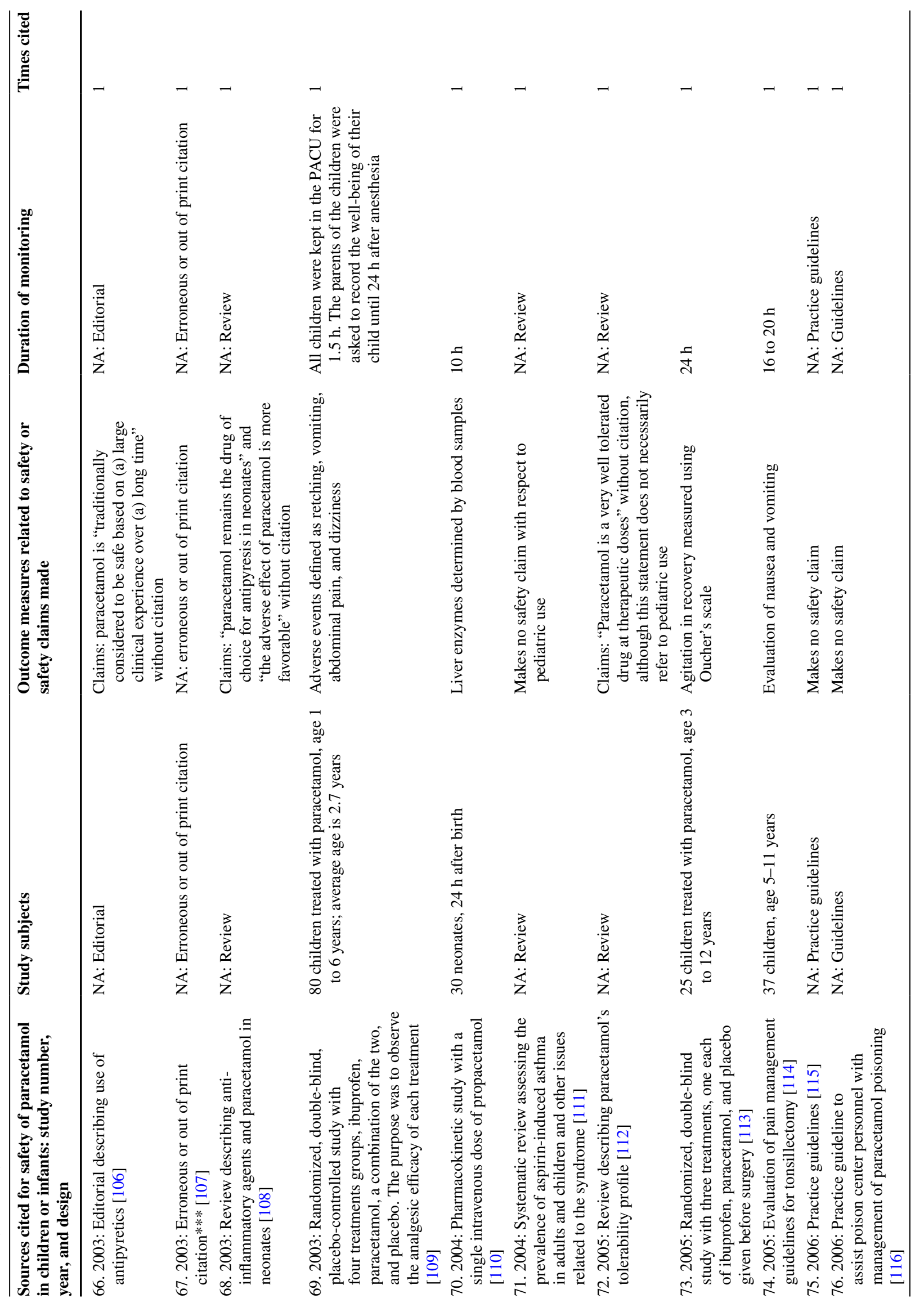




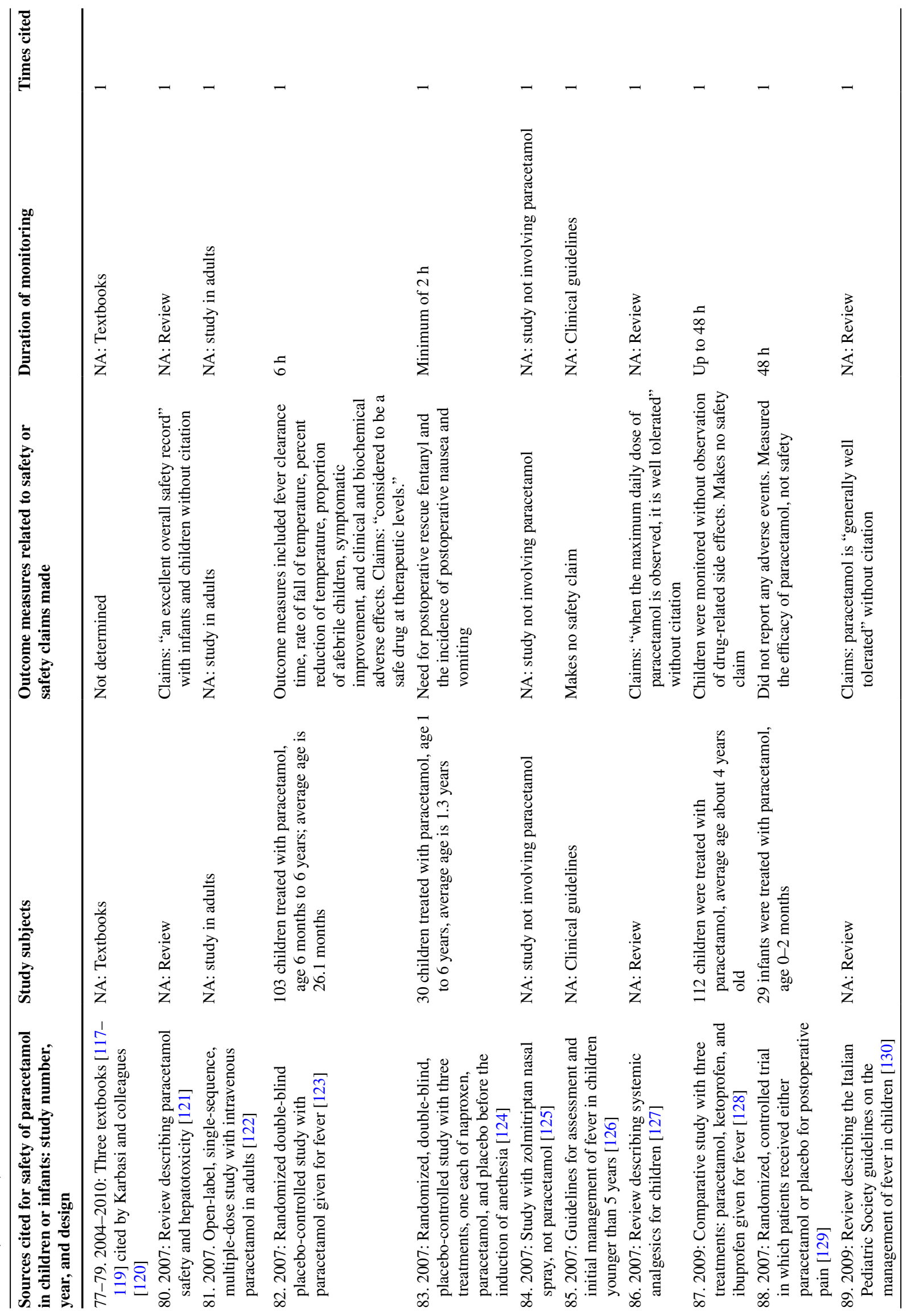




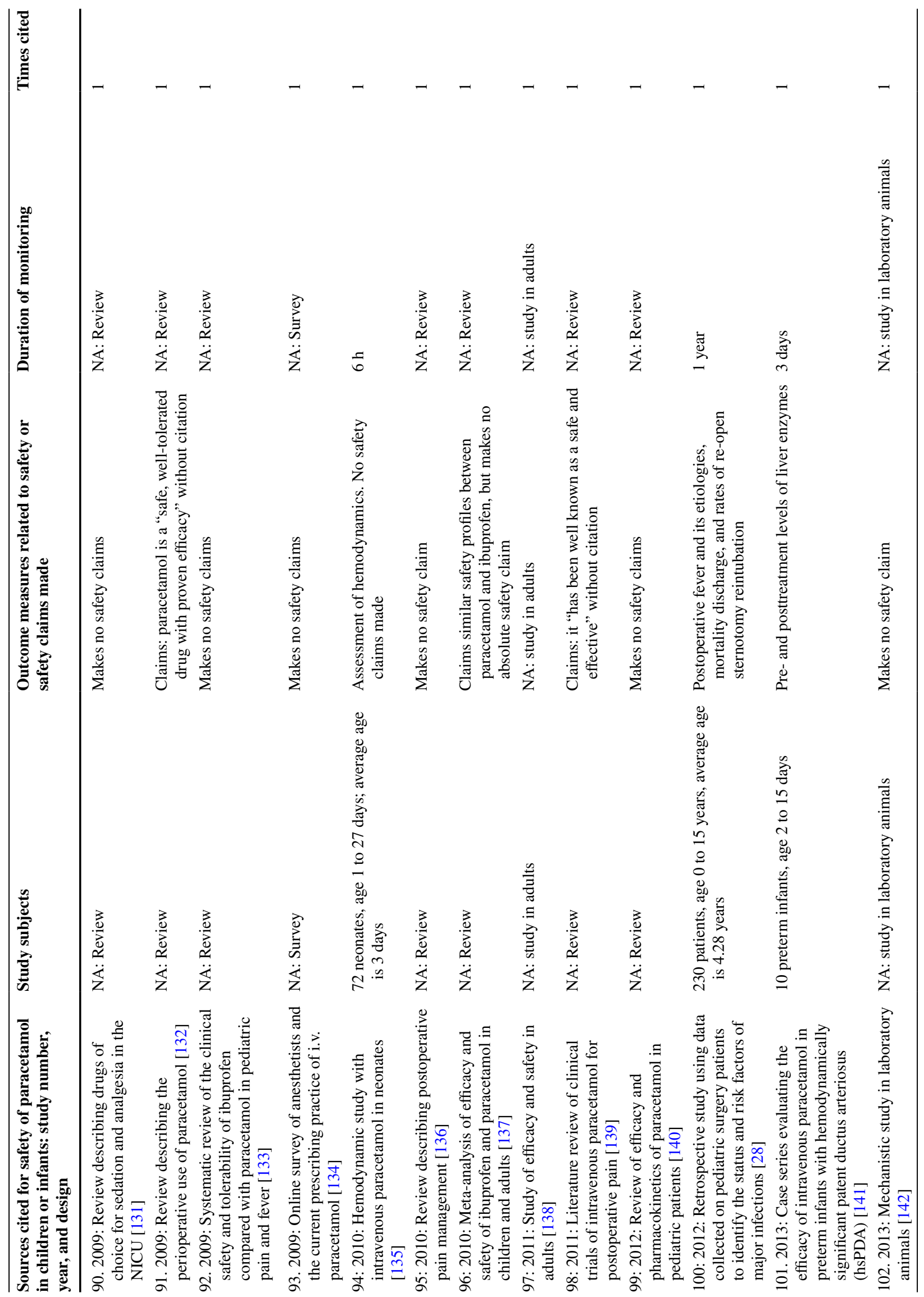




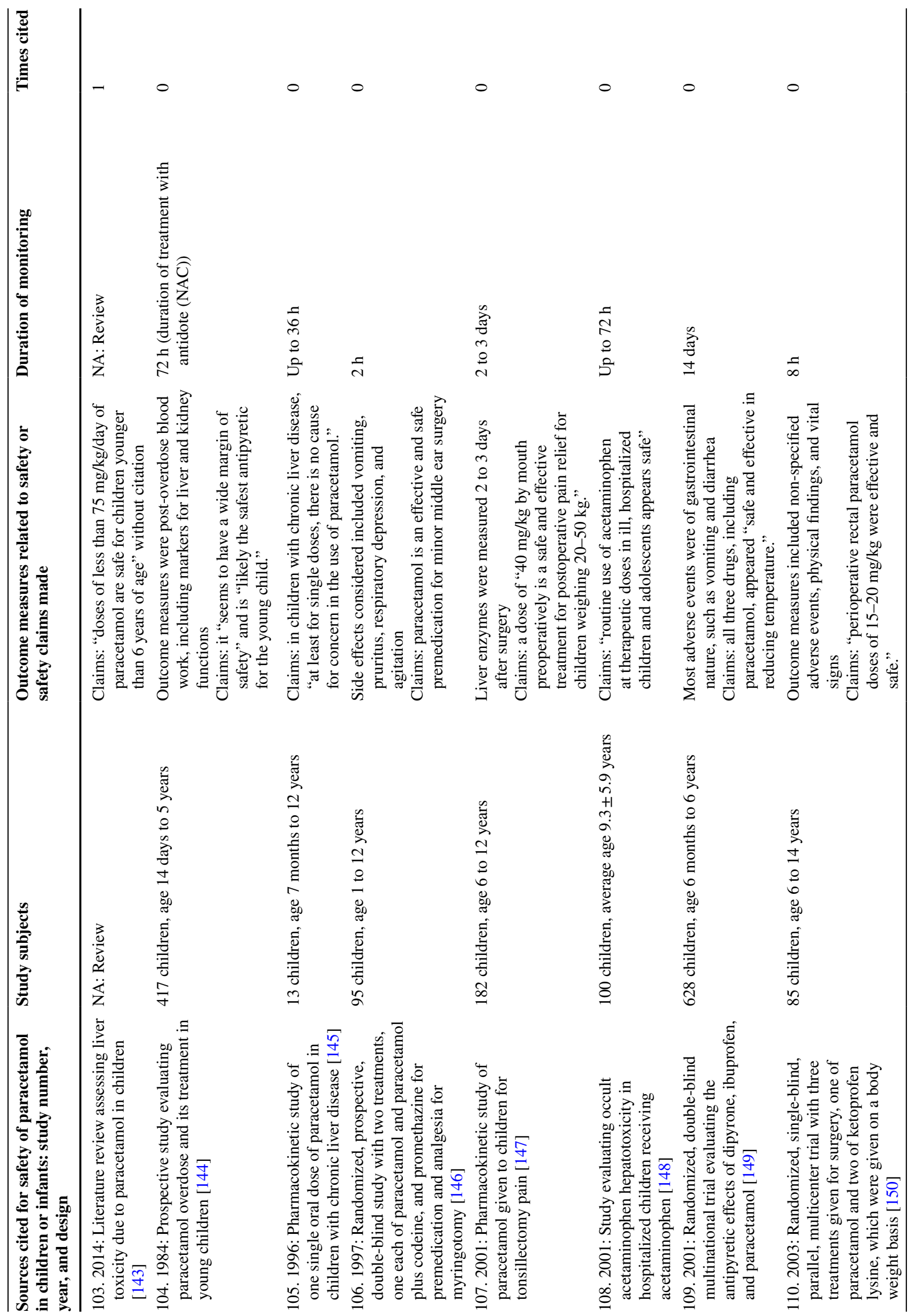




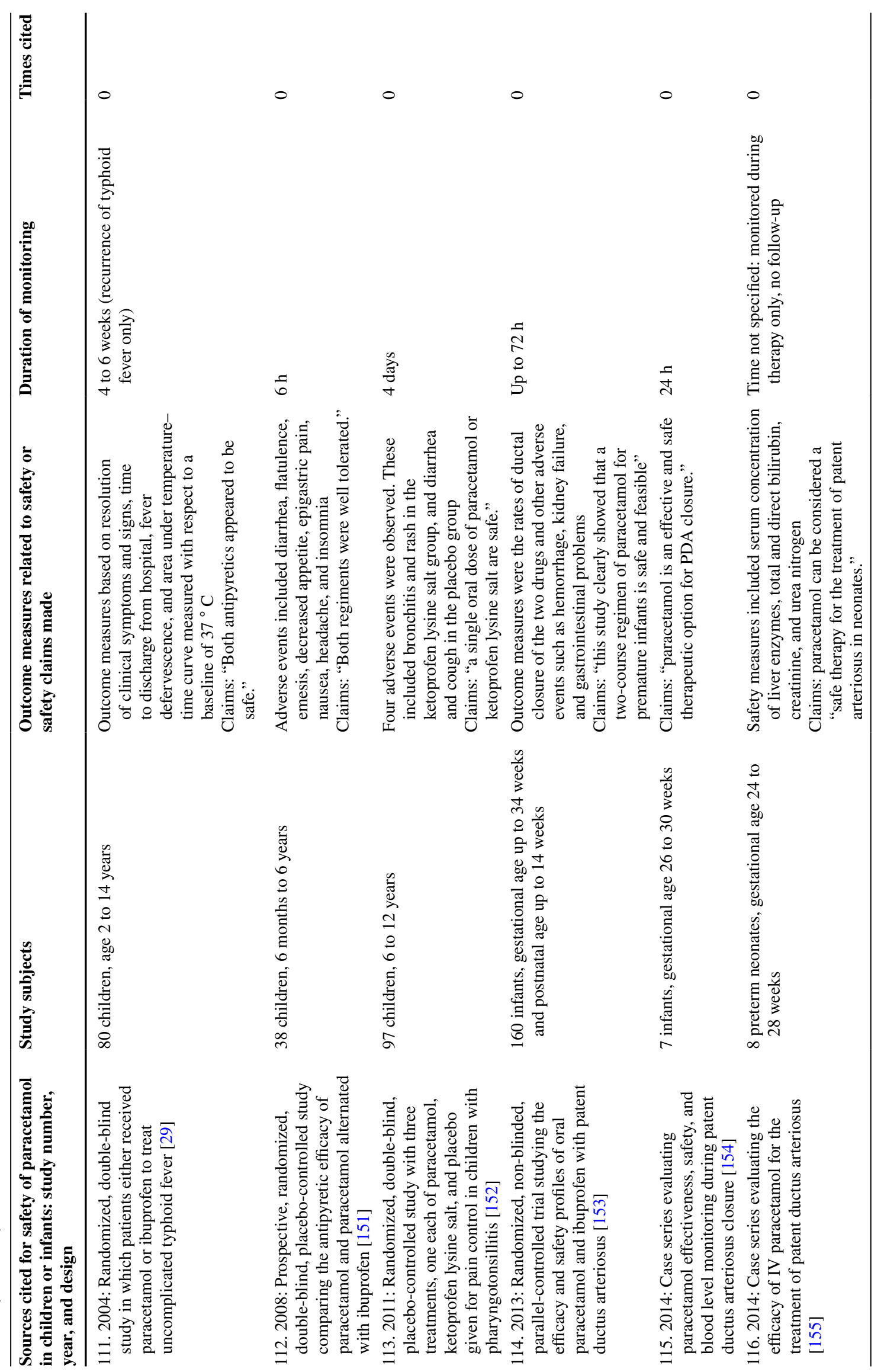




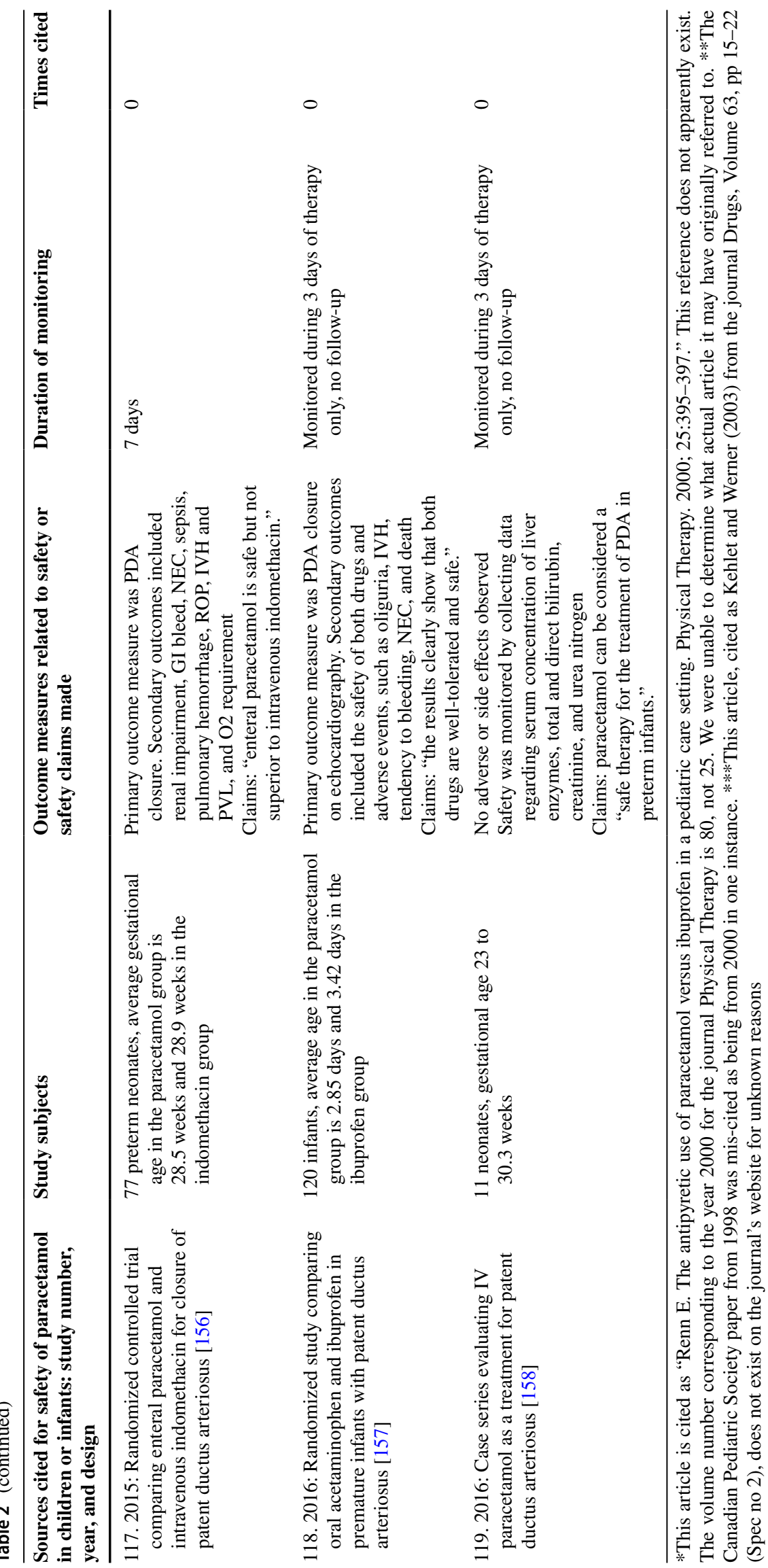


original 218 articles gleaned from the Medline search. Of the 103 articles, 36 articles described experimental studies which involved paracetamol use in infants or children. As described above, from the original 218 articles making claims of safety, 16 uncited articles described experimental studies that were used to support claims of safety. Thus, 52 studies in total (36 cited plus 16 uncited) provided experimental evidence supporting claims of safety. Although several of those 52 studies provided measures of liver function (Table 2), none of the studies provided any assessment of neuropsychiatric function. Furthermore, the median followup time of all 52 studies was $48 \mathrm{~h}$ (Fig. 2), far too short to identify any long-term effects of drug exposure on neuropsychiatric function. Six studies had follow-up times of longer than 10 days, although only one study [28] evaluated patients beyond 6 weeks. However, all experimental studies were blind to any potential effects of drug exposure on long-term neuropsychiatric function. For example, although patients were followed for a full year in one study [28], the only endpoint measured was re-admission for surgery. As another example, a study following patients for up to 6 weeks measured only recurrence of typhoid fever beyond the initial treatment period of the study [29].

The path from more recent papers to the original research addressing the safety of paracetamol in infants and children was sometimes convoluted. In one notable case, a popular citation did not did appear in the literature (Table 2). Not only did the volume and journal number not match, but the title could not be found elsewhere. As another example, the citations reporting safety of paracetamol use in children reported by Temple and colleagues in 2017 [30] are illustrated in Fig. 1. This article provides a detailed description of three prior reports to the European Medicines Agency (reports $24,570,24,571$, and 47,402) which, together, according to the authors, "confirm that the recommended standard paracetamol dose of 10 to $15 \mathrm{mg} / \mathrm{kg}$ is a safe and effective dose for use in pediatric patients when administered as a single dose or as multiple doses for up to $72 \mathrm{~h}$." However, the only safety measure used in the three studies was ALT levels as a marker for liver function, assessed for a maximum of $72 \mathrm{~h}$. In addition to the three reports described in their publication, Temple and colleagues cite 10 additional articles as sources for safety, including the claim that paracetamol has a "well-established efficacy and favorable safety profile" (Fig. 1). Among these 10 papers is a clinical trial [31] that addresses efficacy but not safety, and refers to two other papers that address safety, one by Lesko [26]. The paper by Lesko contradicts the view that paracetamol is safe, finding that paracetamol is significantly worse than ibuprofen in terms of risk for outpatient visits following treatment of children with asthma. Another of the articles cited by Temple in 2017, a review written by Temple more than 30 years before [32], cites a paper in the Federal Register [33] as

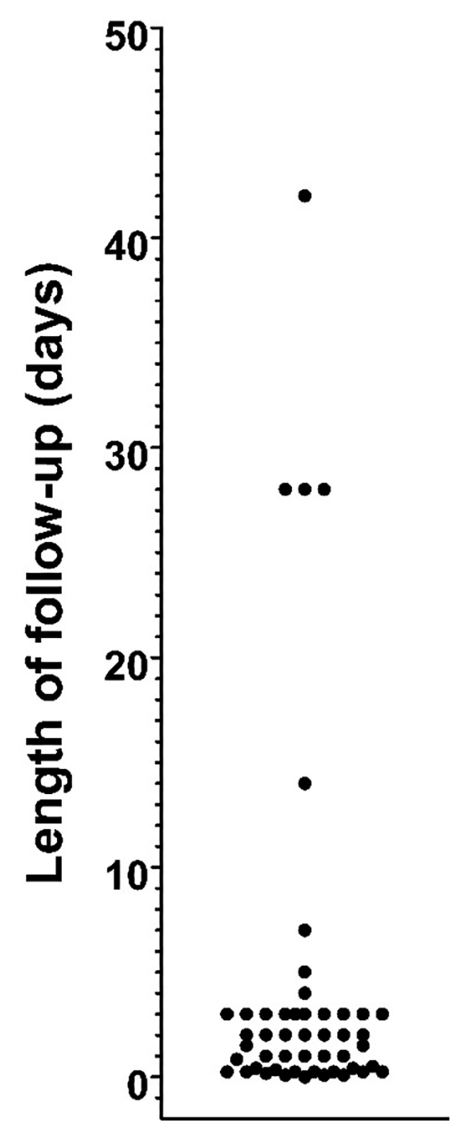

Fig. 2 Maximum follow-up times for 49 of the 52 studies describing experiments designed to test the safety of paracetamol in infants or children. One study [28] monitoring readmission for surgery for 1 year is omitted from the graph. Two other studies [76, 155] observing patients during their inpatient visit or treatment period did not specify duration of monitoring, and therefore could not be included in the graph. The five studies monitoring outcomes for 4 weeks or longer did not monitor neuropsychiatric function

the source for the statement that "Paracetamol is relatively free of side effects and has a wide margin of safety between therapeutic doses and toxic doses." The document in the Federal Register [33], a lengthy treatise primarily focused on determination of the appropriate dose for adults of salicylates in general and aspirin in particular, in turn cites two papers involving safety studies of paracetamol in the human pediatric population. One of those studies [34] evaluated 98 children using a blinded approach comparing aspirin and paracetamol, and monitored the children for only $6 \mathrm{~h}$. The other study [35] monitored 20 children following administration of both aspirin and paracetamol. In that study, monitoring occurred for $6 \mathrm{~h}$ or less, and no information was provided regarding particular side effects that were being assessed. Importantly, the Federal Register [33] attributed their view that paracetamol has "a wide range of safety" to laboratory animal studies showing that the lethal dose of paracetamol is significantly greater than the dose administered to humans. 
Unfortunately, studies had not been conducted at that time showing that paracetamol induces permanent neurodevelopmental injury in laboratory animals at far lower doses than the lethal dose $[19,20]$, similar to doses administered to infants and children.

\section{Discussion}

Our initial search of the PubMed ${ }^{\circledR}$ Database and review of more than 3000 titles and abstracts yielded 218 papers making claims that paracetamol is safe for infants and children when used as directed. Claims of safety in those 218 papers were traced back to 103 articles shown in Table 2, but less than 20 of those were cited more than twice, indicating that a limited number of studies are considered key or cornerstone to the view that paracetamol is safe for use in infants or children.

Finding more than 200 articles making claims that paracetamol is safe and/or well tolerated for infants and children when used as directed, this study confirms the view that the drug is widely thought to be safe, despite the absence of any study demonstrating that it is safe for neurodevelopment. The fact that 27 out of 103 articles citated as authority for the safety of the drug did not, in fact, demonstrate safety or make safety claims might suggest that the safety of paracetamol is taken for granted, and is not carefully considered. This view is supported by the observation that one popular citation for safety does not exist in the literature.

This study does not in any way suggest that the effects of early life exposure to paracetamol on neurodevelopment have never been examined. Indeed, the first study to address the issue was published in 2008 by several now-prominent scientists, then at the University of California San Diego and at San Diego State University [22]. This case-controlled, survey-based study raised substantial concerns, as mentioned in the Introduction. Further, studies in animal models evaluating the issue have been conducted [19-21,36], all indicating that the drug is not safe for neurodevelopment despite a wide range of study designs. In addition, as described in the Introduction, at least 14 cohort analyses [5-18] have indicated that exposure to paracetamol during pregnancy is not safe for neurodevelopment of the fetus. Thus, the present study does not demonstrate that the safety of paracetamol for neurodevelopment has never been examined, but rather demonstrates that assertions that paracetamol is safe during early development when used as recommended are based on a lack of knowledge regarding the effects of paracetamol on neurodevelopment.

The difficulty in moving forward into the clinical arena based on current scientific knowledge is perhaps reflected in the debate surrounding a recent consensus statement supported by almost 100 clinicians and scientists [37] urging caution with the use of paracetamol during pregnancy. This consensus statement of 2021 was met with some skepticism, including an announcement by the American College of Obstetricians and Gynecologists (ACOG) asserting that "Most importantly, patients should not be frightened away from the many benefits of acetaminophen (paracetamol)" [38]. Furthermore, the ACOG asserts that "This consensus statement, and studies that have been conducted in the past, show no clear evidence that proves a direct relationship between the prudent use of acetaminophen (paracetamol) during any trimester and fetal developmental issues" [38]. This latter assertion by the ACOG could technically be considered correct if studies in animal models are ignored, but it demands a level of proof that is not met by the over one dozen studies of cohort data with a wide range of controls for confounding factors via multivariate analysis.

In their response to the 2021 consensus statement, the ACOG clarified their demands for proof, stating that "ACOG's clinical guidance remains the same and physicians should not change clinical practice until definitive prospective research is done" [38]. However, it is difficult to rationalize the need for such a high level of certainty regarding a drug never demonstrated to be safe or life-saving, where judgment should presumably err on the side of caution and avoidance of harm. Indeed, the drug would not meet current safety standards during preclinical testing due to adverse, long-term neurological effects in laboratory animals, and thus would never reach phase I testing under the current regulatory system. Furthermore, the potential difficulty in obtaining the prospective, controlled study demanded by the ACOG is of concern. Although a study during pregnancy might be envisioned, exposures after birth are likely also important (see Introduction), and therefore must be taken into account in any long-term study. The magnitude and difficulty of a sufficiently powered study, starting from conception and extending into early childhood, is considerable. For example, a group at the University of Oulu conducted a 5-year prospective, placebo-controlled study on 49 children following exposure to paracetamol $(n=19)$ or to saline control $(n=20)$ [39]. However, as the authors point out, their study is underpowered to test the impact of paracetamol on neurodevelopment. In addition, the authors did not control for exposure during all 5 years of the study, but rather only for exposure during a single, 4-day period. Furthermore, it is difficult to imagine a placebo control for treating fevers in babies and children, since withholding paracetamol may need to be accompanied by nonmedicinal methods of treating some fevers [40]. Even more importantly, the University of Oulu study used the intravenous formulation of paracetamol rather than the much more commonly used oral formulation. The intravenous formula contains an antidote for paracetamol toxicity (cysteine, a glutathione precursor), which should, hypothetically, block much of the adverse effects of paracetamol. Since this antidote is not present in the commonly used oral formulation, the University of Oulu study, even if it had been much larger and controlled for drug exposure over a period of years, would still not apply to most 
cases of paracetamol use. It should be noted that, in laboratory animals, exposure during the postpartum period to currently accepted levels of the intravenous formulation of paracetamol with the antidote present causes dramatic increases in asocial behavior later in life [36]. Thus, the argument is not that use of paracetamol with the antidote is safe, but rather that, hypothetically, some of the more serious adverse effects might be prevented by inclusion of the antidote with the drug.

The difficulty in obtaining prospective, controlled studies evaluating the safety of paracetamol in humans is, as outlined above, a complex problem involving large numbers of patients and years of study time, difficulty in establishing controls, and the variable presence of an antidote for paracetamol toxicity in paracetamol formulations. These issues point toward the importance of careful examination of presently available evidence or, as the case may be, the lack of evidence regarding the safety of paracetamol for neurodevelopment.

\section{Conclusions}

Although not the intended purpose of this systematic review with citation tracking, it demonstrated that paracetamol has been proven safe for liver function in infants and in small children, even at doses higher than those currently recommended. During the course of this review with citation tracking, an assumption was repeatedly encountered: because the target of paracetamol toxicity in adults is the liver, demonstration of safety in infants and children need only be tested in the liver. This assumption was/is held despite the fact that the target tissue for drug function is in the central nervous system, not the liver. A similar assumption has proven tragically fatal in the past, when it was assumed that metabolism of the antibiotic chloramphenicol was the same in infants as in adults. In that case, administration of the drug in infants led to a number of deaths [41-43] before the problem was identified.

Despite apparently being taken for granted, this study demonstrates that paracetamol was never shown to be safe for neurodevelopment. This conclusion is consistent with emerging studies showing a connection between paracetamol use during development and long-term neuropsychiatric disfunction as described in the Introduction. This conclusion is also consistent with emerging studies in animal models showing exquisite sensitivity of long-term behavior to early life exposure to paracetamol at near-therapeutic doses.

Supplementary information The online version contains supplementary material available at https://doi.org/10.1007/s00431-022-04407-w.

Acknowledgements The authors wish to thank John and Susan Poulton for their encouragement and support of this work.
Authors' contributions JCH, JTS, VGL, AP, and WP reviewed and analyzed the thousands of published papers identified in this study. LGA, VL, and WP designed the study and drafted the manuscript. All authors contributed to editing the manuscript. In addition, VL performed the literature search.

Data availability The dataset analyzed $\left(\mathrm{PubMed}^{\circledR}\right)$ is in the public domain.

Code availability Not applicable.

\section{Declarations}

Ethical approval and consent to participate Not applicable.

Consent to participate Not applicable.

Consent for publication Not applicable.

Competing interests The authors declare no competing interests.

Open Access This article is licensed under a Creative Commons Attribution 4.0 International License, which permits use, sharing, adaptation, distribution and reproduction in any medium or format, as long as you give appropriate credit to the original author(s) and the source, provide a link to the Creative Commons licence, and indicate if changes were made. The images or other third party material in this article are included in the article's Creative Commons licence, unless indicated otherwise in a credit line to the material. If material is not included in the article's Creative Commons licence and your intended use is not permitted by statutory regulation or exceeds the permitted use, you will need to obtain permission directly from the copyright holder. To view a copy of this licence, visit http://creativecommons.org/licenses/by/4.0/.

\section{References}

1. Alemany S et al (2021) Prenatal and postnatal exposure to acetaminophen in relation to autism spectrum and attentiondeficit and hyperactivity symptoms in childhood: meta-analysis in six European population-based cohorts. Eur J Epidemiol 36(10):993-1004

2. Doedée AMCM et al (2014) Effects of prophylactic and therapeutic paracetamol treatment during vaccination on hepatitis $B$ antibody levels in adults: two open-label, randomized controlled trials. PLoS ONE 9(6):e98175-e98175

3. Betz MG, Grunfeld AF (2006) 'Fever phobia' in the emergency department: a survey of children's caregivers. Eur J Emerg Med 13(3):129-133

4. Parker $\mathrm{W}$ et al (2017) The role of oxidative stress, inflammation and acetaminophen exposure from birth to early childhood in the induction of autism. J Int Med Res 45(2):407-438

5. Stergiakouli E, Thapar A, Smith GD (2016) Association of acetaminophen use during pregnancy with behavioral problems in childhood: evidence against confounding. JAMA pediatrics 170(10):964-970

6. Brandlistuen RE et al (2013) Prenatal paracetamol exposure and child neurodevelopment: a sibling-controlled cohort study. Int J Epidemiol 42(6):1702-1713 
7. Liew $\mathrm{Z}$ et al (2014) Acetaminophen use during pregnancy, behavioral problems, and hyperkinetic disorders. JAMA Pediatr 168(4):313-320

8. Liew $\mathrm{Z}$ et al (2016) Paracetamol use during pregnancy and attention and executive function in offspring at age 5 years. Int J Epidemiol 45(6):2009-2017

9. Thompson JM et al (2014) Associations between acetaminophen use during pregnancy and ADHD symptoms measured at ages 7 and 11 years. PLoS One 9(9): p. e108210

10. Liew $Z$ et al (2016) Prenatal use of acetaminophen and child IQ: a Danish cohort study. Epidemiology 27(6):912-918

11. Liew $Z$ et al (2016) Maternal use of acetaminophen during pregnancy and risk of autism spectrum disorders in childhood: a Danish national birth cohort study. Autism Res 9(9):951-958

12. Avella-Garcia CB et al (2016) Acetaminophen use in pregnancy and neurodevelopment: attention function and autism spectrum symptoms. Int J Epidemiol 45(6):1987-1996

13. Skovlund E et al (2017) Language competence and communication skills in 3-year-old children after prenatal exposure to analgesic opioids. Pharmacoepidemiol Drug Saf 26(6):625-634

14. Vlenterie R et al (2016) Neurodevelopmental problems at 18 months among children exposed to paracetamol in utero: a propensity score matched cohort study. Int J Epidemiol 45(6):1998-2008

15. Ystrom E et al (2017) Prenatal exposure to acetaminophen and risk of ADHD. Pediatrics 140(5)

16. Ji Y et al (2019) Association of cord plasma biomarkers of in utero acetaminophen exposure with risk of attention-deficit/ hyperactivity disorder and autism spectrum disorder in childhood. JAMA Psychiatry 1-11

17. Bittker SS, Bell KR (2018) Acetaminophen, antibiotics, ear infection, breastfeeding, vitamin D drops, and autism: an epidemiological study. Neuropsychiatr Dis Treat 14:1399-1414

18. Tovo-Rodrigues L et al (2018) Is intrauterine exposure to acetaminophen associated with emotional and hyperactivity problems during childhood? Findings from the 2004 Pelotas birth cohort. BMC Psychiatry 18(1):368

19. Philippot $\mathrm{G}$ et al (2017) Adult neurobehavioral alterations in male and female mice following developmental exposure to paracetamol (acetaminophen): characterization of a critical period. J Appl Toxicol 37(10):1174-1181

20. Viberg H et al (2013) Paracetamol (Acetaminophen) administration during neonatal brain development affects cognitive function and alters its analgesic and anxiolytic response in adult male mice. Toxicol Sci 138(1):139-147

21. Hay-Schmidt A et al (2017) Prenatal exposure to paracetamol/ acetaminophen and precursor aniline impairs masculinisation of male brain and behaviour. Reproduction 154(2):145-152

22. Schultz ST et al (2008) Acetaminophen (paracetamol) use, measles-mumps-rubella vaccination, and autistic disorder. The results of a parent survey. Autism 12(3):293-307.

23. Frisch M, Simonsen J (2015) Ritual circumcision and risk of autism spectrum disorder in 0- to 9-year-old boys: national cohort study in Denmark. J R Soc Med 108(7):266-279

24. Goin-Kochel RP, Mire SS, Dempsey AG (2015) Emergence of autism spectrum disorder in children from simplex families: relations to parental perceptions of etiology. J Autism Dev Disord 45(5):1451-1463

25. Mercer L et al (2006) Parental perspectives on the causes of an autism spectrum disorder in their children. J Genet Couns 15(1):41-50

26. Lesko SM, Mitchell AA (1999) The safety of acetaminophen and ibuprofen among children younger than two years old. Pediatrics 104(4):e39
27. Perrott DA et al (2004) Efficacy and safety of acetaminophen vs ibuprofen for treating children's pain or fever: a meta-analysis. Arch Pediatr Adolesc Med 158(6):521-526

28. Vijarnsorn C et al (2012) Postoperative fever and major infections after pediatric cardiac surgery. J Med Assoc Thai 95(6):761-770

29. Vinh $\mathrm{H}$ et al (2004) Double blind comparison of ibuprofen and paracetamol for adjunctive treatment of uncomplicated typhoid fever. Pediatr Infect Dis J 23(3):226-230

30. Temple AR et al (2017) Comparison of the efficacy and safety of 2 acetaminophen dosing regimens in febrile infants and children: a report on 3 legacy studies. The journal of pediatric pharmacology and therapeutics: JPPT: the official journal of PPAG 22(1):22-32

31. Shepherd M, Aickin R (2009) Paracetamol versus ibuprofen: a randomized controlled trial of outpatient analgesia efficacy for paediatric acute limb fractures. Emerg Med Australas 21(6):484-490

32. Temple AR (1983) Review of comparative antipyretic activity in children. Am J Med 75(5a):38-46

33. Federal Register (1977) 42(131):35366-35413

34. Tarlin L et al (1972) A comparison of the antipyretic effect of acetaminophen and aspirin. Another approach to poison prevention. Am J Dis Child 124(6):880-2

35. Steele RW et al (1972) Oral antipyretic therapy: evaluation of aspirin-acetaminophen combination. Am J Dis Child 123(3):204-206

36. Suda N et al (2022) Therapeutic doses of paracetamol with coadministration of cysteine and mannitol during early development result in long term behavioral changes in laboratory rats. PLoS One 16(6):e0253543

37. Bauer AZ et al (2021) Paracetamol use during pregnancy - a call for precautionary action. Nat Rev Endocrinol 17(12):757-766

38. ACOG (2021) ACOG Response to consensus statement on paracetamol use during pregnancy. ACOG News

39. Juujärvi $S$ et al (2021) Trial of paracetamol for premature newborns: five-year follow-up. J Matern Fetal Neonatal Med 1-3

40. AAP (2015) Treating a fever without medicine. Caring for your baby and young child: birth to age 5. Available from: https:// www.healthychildren.org/English/health-issues/conditions/fever/ Pages/Treating-a-Fever-Without-Medicine.aspx

41. Lischner $\mathrm{H}$ et al (1961) An outbreak of neonatal deaths among term infants associated with administration of chloramphenicol. J Pediatr 59(1):21-34

42. Sutherland JM (1959) Fatal cardiovascular collapse of infants receiving large amounts of chloramphenicol. AMA J Dis Child 97(6):761-767

43. Burns LE, Hodgman JE, Cass AB (1959) Fatal circulatory collapse in premature infants receiving chloramphenicol. N Engl $\mathbf{J}$ Med 261:1318-1321

44. Hämäläinen ML et al (1997) Ibuprofen or acetaminophen for the acute treatment of migraine in children: a double-blind, randomized, placebo-controlled, crossover study. Neurology 48(1):103-107

45. Rumack BH (1978) Aspirin versus acetaminophen: a comparative view. Pediatrics 62(5 Pt 2 Suppl):943-6

46. Litalien C, Jacqz-Aigrain E (2001) Risks and benefits of nonsteroidal anti-inflammatory drugs in children: a comparison with paracetamol. Paediatr Drugs 3(11):817-858

47. Drwal-Klein LA, Phelps SJ (1992) Antipyretic therapy in the febrile child. Clin Pharm 11(12):1005-1021

48. Sullivan JE, Farrar HC (2011) Fever and antipyretic use in children. Pediatrics 127(3):580-587

49. Temple AR (1983) Pediatric dosing of acetaminophen. Pediatr Pharmacol (New York) 3(3-4):321-327

50. Lesko SM, Mitchell AA (1995) An assessment of the safety of pediatric ibuprofen. A practitioner-based randomized clinical trial Jama 273(12):929-933 
51. Society, C.P. (1998) Acetaminophen and ibuprofen in the management of fever and mild to moderate pain in children. Pediatr Child Health 3(4):273-274

52. American Academy of Pediatrics Committee on Drugs (1978) commentary on acetaminophen. Pediatrics 61(1):108-112

53. Lovejoy FH JR (1978) Aspirin and acetaminophen: a comparative view of their antipyretic and analgesic activity. Pediatrics 62(5 Pt 2 Suppl):904-9

54. Prescott LF (1996) Paracetamol overdose, in Paracetamol (acetaminophen): a critical bibliographic review. Taylor \& Francis Ltd. 451

55. Lesko SM, Mitchell AA (1997) Renal function after short-term ibuprofen use in infants and children. Pediatrics 100(6):954-957

56. Anderson BJ et al (2005) Pediatric intravenous paracetamol (propacetamol) pharmacokinetics: a population analysis. Paediatr Anaesth 15(4):282-292

57. Zuppa AF et al (2011) Safety and population pharmacokinetic analysis of intravenous acetaminophen in neonates, infants, children, and adolescents with pain or fever. J Pediatr Pharmacol Ther 16(4):246-261

58. Sutton E, Soyka LF (1973) How safe is acetaminophen? Some practical cautions with this widely used agent. Clin Pediatr (Phila) 12(12):692-696

59. Yaffe SJ (1981) Comparative efficacy of aspirin and acetaminophen in the reduction of fever in children. Arch Intern Med 141(3):286-292

60. Depré M et al (1992) Tolerance and pharmacokinetics of propacetamol, a paracetamol formulation for intravenous use. Fundam Clin Pharmacol 6(6):259-262

61. Anand KJS, Shapiro BS, Berde CB (1993) Pharmacotherapy with systemic analgesics. In: Anand KJS, McGrath PJ (eds) Pain research and clinical management. Elsevier, New York, pp 155-198

62. McIntyre J, Hull D (1996) Comparing efficacy and tolerability of ibuprofen and paracetamol in fever. Arch Dis Child 74(2):164-167

63. Anderson BJ, Holford NHG (1997) Rectal paracetamol dosing regimens: determination by computer simulation. Pediatr Anesth 7(6):451-455

64. Birmingham PK et al (1997) Twenty-four-hour pharmacokinetics of rectal acetaminophen in children: an old drug with new recommendations. Anesthesiology 87(2):244-252

65. van Lingen, RA et al (1999) Pharmacokinetics and metabolism of rectally administered paracetamol in preterm neonates. Arch Dis Child: Fetal Neonatal Ed 80(1):F59-F63

66. Autret-Leca E, Gibb IA, Goulder MA (2007) Ibuprofen versus paracetamol in pediatric fever: objective and subjective findings from a randomized, blinded study. Curr Med Res Opin 23(9):2205-2211

67. Allegaert K et al (2008) Hepatic tolerance of repeated intravenous paracetamol administration in neonates. Paediatr Anaesth 18(5):388-392

68. Maund E et al (2011) Paracetamol and selective and non-selective non-steroidal anti-inflammatory drugs for the reduction in morphine-related side-effects after major surgery: a systematic review. Br J Anaesth 106(3):292-297

69. Temple AR, Temple BR, Kuffner EK (2013) Dosing and antipyretic efficacy of oral acetaminophen in children. Clin Ther 35(9):1361-75.e1-45

70. Woodbury D (1965) Analgesics and antipyretics. In: Goodman L, Gilman A (eds) The pharmacological basis of therapeutics. The Macmillan Company, Ney York, NY, pp 330-335

71. Eden AN, Kaufman A (1967) Clinical comparison of three antipyretic agents. Am J Dis Child 114(3):284-287
72. Temple AR (1978) Pathophysiology of aspirin overdosage toxicity, with implications for management. Pediatrics 62 (5 Pt 2 Suppl):873-6

73. Mitchell AA et al (1982) Acetaminophen and aspirin: prescription, use, and accidental ingestion among children. Am J Dis Child 136(11):976-979

74. Nahata M, Powell D (1982) Kinetics of acetaminophen (Ac) following single strength (SS-Ac) vs double strength (DS-Ac) administration to febrile children. Clin Res 30(2)

75. Ragg P, Davidson A (1997) Comparison of the efficacy of paracetamol versus paracetamol, codeine and promethazine (Painstop ${ }^{\circledR)}$ for premedication and analgesia for myringotomy in children. Anaesth Intensive Care 25(1):29-32

76. Choonara IA, Harris F (1984) Adverse drug reactions in medical inpatients. Arch Dis Child 59(6):578-580

77. Ibuprofen vs acetaminophen in children (1989) Med Lett Drugs Ther 31(807):109-110

78. Truog R, Anand KJ (1989) Management of pain in the postoperative neonate. Clin Perinatol 16(1):61-78

79. Insel P (1990) Analgesic-antipyretics and anti-inflammatory agents; drugs employed in the treatment of rheumatoid arthritis and gout. In: Gilman A et al (eds) The pharmacological basis of therapeutics. Pergamon Press, Elmsford, NY, pp 656-659

80. Penna A, Buchanan N (1991) Paracetamol poisoning in children and hepatotoxicity. Br J Clin Pharmacol 32(2):143-149

81. Prescott LF (1992) The hepatotoxicity of non-steroidal antiinflammatory drugs, in Side-effects of anti-inflammatory drugs 3, K.D. Rainsford and G.P. Velo, Eds Springer Dordrecht Netherlands 176-187

82. Walson PD et al (1992) Comparison of multidose ibuprofen and acetaminophen therapy in febrile children. Am J Dis Child 146(5):626-632

83. Lorin MI (1994) Pathogenesis of fever and its treatment. In: Oski FA, Deangelis CD (eds) Principles and practice of pediatrics. J.B. Lippincott, Philadelphia, pp 1111-1113

84. Wilson D (1995) Assessing and managing the febrile child. Nurse Pract 20(11 Pt 1):59-60, 68-74

85. Anderson B, Kanagasundarum S, Woollard G (1996) Analgesic efficacy of paracetamol in children using tonsillectomy as a pain model. Anaesth Intensive Care 24(6):669-673

86. Romej M et al (1996) Effect of preemptive acetaminophen on postoperative pain scores and oral fluid intake in pediatric tonsillectomy patients. Aana j 64(6):535-540

87. Vauzelle-Kervroëdan F et al (1997) Equivalent antipyretic activity of ibuprofen and paracetamol in febrile children. J Pediatr 131(5):683-687

88. Korpela RMD, Korvenoja PMD, Olli AMDP (1999) Meretoja, Morphine-sparing effect of acetaminophen in pediatric day-case surgery Anesthesiology. J Am Soc Anesthesiol 91(2):442-447

89. van Lingen RA et al (1999) Multiple-dose pharmacokinetics of rectally administered acetaminophen in term infants. Clin Pharmacol Ther 66(5):509-515

90. Dahl V, Raeder JC (2000) Non-opioid postoperative analgesia. Acta Anaesthesiol Scand 44(10):1191-1203

91. Hahn TW et al (2000) Pharmacokinetics of rectal paracetamol after repeated dosing in children. BJA: British Journal of Anaesthesia 85(4):512-519

92. Mohler CR et al (2000) Prospective evaluation of mild to moderate pediatric acetaminophen exposures. Ann Emerg Med 35(3):239-244

93. Prescott LF (2000) Paracetamol: past, present, and future. Am J Ther 7(2):143-147

94. Rømsing J et al (2000) Diclofenac or acetaminophen for analgesia in paediatric tonsillectomy outpatients. Acta Anaesthesiol Scand 44(3):291-295 
95. World Health O (2000) Handbook : IMCI integrated management of childhood illness. World Health Organization, Geneva

96. Wilson JT et al (2000) Acetaminophen controlled-release sprinkles versus acetaminophen immediate-release elixir in febrile children. J Clin Pharmacol 40(4):360-369

97. Zenk KJ, Sills J, Koeppel R (2000) Neonatal medications \& nutrition: a comprehensive guide. 2nd ed., C. Rait, Editor. NICU INK Book Publishers: Santa Rosa, CA 1-7

98. Arana A, Morton NS, Hansen TG (2001) Treatment with paracetamol in infants. Acta Anaesthesiol Scand 45(1):20-29

99. Buck ML (2001) Perioperative use of high-dose rectal acetaminophen. Pediatric Pharmacotherapy 7(9)

100. Acetaminophen toxicity in children (2001) Pediatrics 108(4): 1020

101. Fitzgerald M, Beggs S (2001) The neurobiology of pain: developmental aspects. Neuroscientist 7(3):246-257

102. Olson NZ et al (2001) Onset of analgesia for liquigel ibuprofen $400 \mathrm{mg}$, acetaminophen $1000 \mathrm{mg}$, ketoprofen $25 \mathrm{mg}$, and placebo in the treatment of postoperative dental pain. J Clin Pharmacol 41(11):1238-1247

103. van der Marel CD et al (2001) Analgesic efficacy of rectal versus oral acetaminophen in children after major craniofacial surgery. Clin Pharmacol Ther 70(1):82-90

104. Hyllested M et al (2002) Comparative effect of paracetamol, NSAIDs or their combination in postoperative pain management: a qualitative review. Br J Anaesth 88(2):199-214

105. Purssell E (2002) Treating fever in children: paracetamol or ibuprofen? Br J Community Nurs 7(6):316-320

106. Amdekar YK (2003) Rational use of antipyretics. Indian Pediatr 40(6):541-544

107. Kehlet H, Werner MU (2003) [Role of paracetamol in the acute pain management]. Drugs 63 Spec No 2: p. 15-22

108. Morris JL, Rosen DA, Rosen KR (2003) Nonsteroidal antiinflammatory agents in neonates. Pediatr Drugs 5(6):385-405

109. Viitanen $\mathrm{H}$ et al (2003) Analgesic efficacy of rectal acetaminophen and ibuprofen alone or in combination for paediatric day-case adenoidectomy. Br J Anaesth 91(3):363-367

110. Allegaert K et al (2004) Pharmacokinetics of single dose intravenous propacetamol in neonates: effect of gestational age. Arch Dis Child: Fetal Neonatal Ed 89(1):F25-F28

111. Jenkins C, Costello J, Hodge L (2004) Systematic review of prevalence of aspirin induced asthma and its implications for clinical practice. BMJ 328(7437):434

112. Graham GG, Scott KF, Day RO (2005) Tolerability of paracetamol. Drug Saf 28(3):227-240

113. Kashefi P, Mirdamadi M (2005) Preemptive analgesia with ibuprofen and acetaminophen in pediatric lower abdominal surgery. 10(4):5

114. White MC, Nolan JA (2005) An evaluation of pain and postoperative nausea and vomiting following the introduction of guidelines for tonsillectomy. Pediatr Anesth 15(8):683-688

115. Batton DG, Barrington KJ, Wallman C (2006) Prevention and management of pain in the neonate: an update. Pediatrics 118(5):2231-2241

116. Dart RC et al (2006) Acetaminophen poisoning: an evidencebased consensus guideline for out-of-hospital management. Clin Toxicol (Phila) 44(1):1-18

117. Lorin MI (2004) Fever. In: Feigin RD et al (eds) Text book of pediatrics infectious disease. Saunders, Philadelphia, PA, pp 100-105

118. Keith RP (2007) Fever. In: Behrman RE, Kliegman RM, Jenson HB (eds) Nelson Textbook of pediatrics. WB Saunders, Philadelphia, PA, pp 1084-1087
119. Jenson HB, Baltimore RS (2006) Infectious disease. In: Behrman RE, Kliegman RM (eds) Nelson essential of pediatrics. Elsevier Saunders, Philadelphia, pp 446-450

120. Karbasi SA, Modares-Mosadegh M, Golestan M (2010) Comparison of antipyretic effectiveness of equal doses of rectal and oral acetaminophen in children. J Pediatr (Rio J) 86(3):228-232

121. Amar P, Schiff E (2007) Acetaminophen safety and hepatotoxicity-where do we go from here? Expert Opin Drug Saf 6:341-355

122. Gregoire N et al (2007) Safety and pharmacokinetics of paracetamol following intravenous administration of $5 \mathrm{~g}$ during the first 24 $\mathrm{h}$ with a 2-g starting dose. Clin Pharmacol Ther 81(3):401-405

123. Gupta $\mathrm{H}$ et al (2007) Role of paracetamol in treatment of childhood fever: a double-blind randomized placebo controlled trial. Indian Pediatr 44(12):903-911

124. Korpela $\mathrm{R}$ et al (2007) Oral naproxen but not oral paracetamol reduces the need for rescue analgesic after adenoidectomy in children. Acta Anaesthesiol Scand 51(6):726-730

125. Lewis DW et al (2007) Efficacy of zolmitriptan nasal spray in adolescent migraine. Pediatrics 120(2):390-396

126. Richardson $\mathrm{M}$ et al (2007) Assessment and initial management of feverish illness in children younger than 5 years: summary of NICE guidance. BMJ (Clinical research ed) 334(7604):1163-1164

127. Rose M (2007) Systemic analgesics for children. Anaesth Intensive Care Med 8(5):184-188

128. Celebi $S$ et al (2009) Antipyretic effect of ketoprofen. The Indian Journal of Pediatrics 76:287-291

129. van der Marel CD et al (2007) Rectal acetaminophen does not reduce morphine consumption after major surgery in young infants. BJA: British Journal of Anaesthesia 98(3):372-379

130. Chiappini E et al (2009) Management of fever in children: summary of the Italian Pediatric Society guidelines. Clin Ther 31(8):1826-1843

131. Hall RW, Shbarou RM (2009) Drugs of choice for sedation and analgesia in the neonatal ICU. Clin Perinatol 36(1):15-26

132. Oscier CD, Milner QJ (2009) Peri-operative use of paracetamol. Anaesthesia 64(1):65-72

133. Southey ER, Soares-Weiser K, Kleijnen J (2009) Systematic review and meta-analysis of the clinical safety and tolerability of ibuprofen compared with paracetamol in paediatric pain and fever. Curr Med Res Opin 25(9):2207-2222

134. Wilson-Smith EM, Morton NS (2009) Survey of i.v. paracetamol (acetaminophen) use in neonates and infants under 1 year of age by UK anesthetists. Paediatr Anaesth 19(4):329-37

135. Allegaert K, Naulaers G (2010) Haemodynamics of intravenous paracetamol in neonates. Eur J Clin Pharmacol 66(9):855-858

136. Elvir-Lazo OL, White PF (2010) The role of multimodal analgesia in pain management after ambulatory surgery. Curr Opin Anaesthesiol 23(6):697-703

137. Pierce CA, Voss B (2010) Efficacy and safety of ibuprofen and acetaminophen in children and adults: a meta-analysis and qualitative review. Ann Pharmacother 44(3):489-506

138. Kett DH et al (2011) A randomized study of the efficacy and safety of intravenous acetaminophen vs. intravenous placebo for the treatment of fever. Clin Pharmacol Ther 90(1):32-9

139. Macario A, Royal MA (2011) A literature review of randomized clinical trials of intravenous acetaminophen (paracetamol) for acute postoperative pain. Pain Pract 11(3):290-296

140. Ji P et al (2012) Regulatory review of acetaminophen clinical pharmacology in young pediatric patients. J Pharm Sci 101(12):4383-4389

141. Oncel MY et al (2013) Intravenous paracetamol treatment in the management of patent ductus arteriosus in extremely low birth weight infants. Neonatology 103(3):166-169 
142. Engström Ruud L et al (2013) Acetaminophen reduces lipopolysaccharide-induced fever by inhibiting cyclooxygenase-2. Neuropharmacology 71:124-129

143. Heard K et al (2014) Toxicity from repeated doses of acetaminophen in children: assessment of causality and dose in reported cases. Am J Ther 21(3):174-183

144. Rumack BH (1984) Acetaminophen overdose in young children. Treatment and effects of alcohol and other additional ingestants in 417 cases. Am J Dis Child 138(5):428-33

145. al-Obaidy SS et al (1996) Metabolism of paracetamol in children with chronic liver disease. Eur J Clin Pharmacol 50(1-2):69-76

146. Ragg P, Davidson A (1997) Comparison of the efficacy of paracetamol versus paracetamol, codeine and promethazine (Painstop) for premedication and analgesia for myringotomy in children. Anaesth Intensive Care 25(1):29-32

147. Anderson BJ, Woollard GA, Holford NH (2001) Acetaminophen analgesia in children: placebo effect and pain resolution after tonsillectomy. Eur J Clin Pharmacol 57(8):559-569

148. James LP et al (2001) Evaluation of occult acetaminophen hepatotoxicity in hospitalized children receiving acetaminophen. Pediatric Pharmacology Research Unit Network. Clin Pediatr (Phila) 40(5):243-8

149. Wong A et al (2001) Antipyretic effects of dipyrone versus ibuprofen versus acetaminophen in children: results of a multinational, randomized, modified double-blind study. Clin Pediatr (Phila) 40(6):313-324

150. Messeri A et al (2003) Analgesic efficacy and tolerability of ketoprofen lysine salt vs paracetamol in common paediatric surgery. A randomized, single-blind, parallel, multicentre trial. Paediatr Anaesth 13(7):574-8

151. Kramer LC et al (2008) Alternating antipyretics: antipyretic efficacy of acetaminophen versus acetaminophen alternated with ibuprofen in children. Clin Pediatr (Phila) 47(9):907-911
152. Ruperto $\mathrm{N}$ et al (2011) A randomized, double-blind, placebocontrolled trial of paracetamol and ketoprofren lysine salt for pain control in children with pharyngotonsillitis cared by family pediatricians. Ital J Pediatr 37:48

153. Dang D et al (2013) Comparison of oral paracetamol versus ibuprofen in premature infants with patent ductus arteriosus: a randomized controlled trial. PLoS One 8(11):e77888

154. Kessel I et al (2014) Paracetamol effectiveness, safety and blood level monitoring during patent ductus arteriosus closure: a case series. J Matern Fetal Neonatal Med 27(16):1719-1721

155. Terrin $\mathrm{G}$ et al (2014) Efficacy of paracetamol for the treatment of patent ductus arteriosus in preterm neonates. Ital $\mathrm{J}$ Pediatr 40(1): 21

156. Dash SK et al (2015) Enteral paracetamol or intravenous indomethacin for closure of patent ductus arteriosus in preterm neonates: a randomized controlled trial. Indian Pediatr 52(7):573-578

157. Bagheri MM et al (2016) Comparison of oral acetaminophen versus ibuprofen in premature infants with patent ductus arteriosus. Iran J Pediatr 26(4):e3975

158. Memisoglu A et al (2016) Ductal closure with intravenous paracetamol: a new approach to patent ductus arteriosus treatment. J Matern Fetal Neonatal Med 29(6):987-990

159. Cranswick N, Coghlan D (2000) Paracetamol efficacy and safety in children: the first 40 years. Am J Ther 7:135-142

Publisher's Note Springer Nature remains neutral with regard to jurisdictional claims in published maps and institutional affiliations. 